\title{
A IMPLANTAÇÃO DO MENORISMO NA AMÉRICA LATINA NO INÍCIO DO SÉCULO XX: TENDÊNCIAS JURÍDICAS E POLÍTICAS PARA A CONTENÇÃO DOS MAIS POBRES
}

\author{
LA IMPLANTACIÓN DEL MINORISMO EN AMÉRICA LATINA A PRINCIPIOS DEL \\ SIGLO XX: TENDENCIAS JURÍDICAS Y POLÍTICAS PARA LA CONTENCIÓN DE \\ LOS MÁS POBRES
}

\section{THE IMPLANTATION OF MINORISMO IN LATIN AMERICA IN THE EARLY TWENTIETH CENTURY: LEGAL AND POLITICAL TENDENCIES FOR THE CONTAINMENT OF THE POOREST}

\author{
Maria Nilvane ZANELLA ${ }^{1}$
}

RESUMO: O artigo realiza uma análise sobre a influência dos Estados Unidos da América (EUA) na produção jurídica para a área da infância no final do século XIX, início do século XX. O embate entre o socialismo e o capitalismo, a doutrina Monroe, a psicologia desenvolvimentista de Stanley Hall, a criança e adolescência perigosa, a proposta de salvação da infância, os Congressos e eventos internacionais foram algumas das determinações que contribuíram para a implantação do modelo tutelar pautado na doutrina da situação irregular na América Latina. Para evidenciar como diferentes fatores convergiram para alterar a ordem jurídica e social analisamos esse percurso em cinco países, sendo eles, Argentina, Brasil, Chile, México e Uruguai.

PALAVRAS-CHAVE: América Latina. Políticas de socioeducação. Menorismo. Psicologia do desenvolvimento.

RESUMEN: El artículo realiza un análisis sobre la influencia de los Estados Unidos en la producción jurídica para el área de la infancia a finales del siglo XIX, a principios del siglo XX. El embate entre el socialismo y el capitalismo, la doctrina Monroe, la psicología del desarrollo de Stanley Hall, el niño y la adolescencia peligrosa, la propuesta de salvación de la infancia, los Congresos y eventos internacionales fueron algunas de las determinaciones que contribuyeron a la implantación del modelo tutelar pautado en la doctrina de la situación irregular en América Latina. Para evidenciar cómo diferentes factores convergieron para alterar el orden jurídico y social analizamos ese recorrido en cinco países, siendo ellos, Argentina, Brasil, Chile, México y Uruguay.

PALABRAS CLAVE: América Latina. Políticas de socioeducación. Menorismo. Psicología del desarrollo.

${ }^{1}$ Universidade Federal do Amazonas (UFAM), Manaus - AM - Brasil. Professora Adjunta da Faculdade de Educação da Universidade Federal do Amazonas (UFAM). Pedagoga. Mestre e doutora em Educação (UEM). Mestre em adolescentes em conflito com a lei. Pesquisadora da área da infância e juventude, desde 2005. ORCID: http://orcid.org/0000-0002-3420-2714. E-mail: nilvane@gmail.com

RIAEE - Revista Ibero-Americana de Estudos em Educação, Araraquara, v. 14, n. esp. 3, p. 1750-1766, out., 2019. e-ISSN: 1982-5587. 
ABSTRACT: The article analyzes the influence of the United States of America on legal production for children in the late nineteenth and early twentieth century. The clash between socialism and capitalism, the Monroe Doctrine, Stanley Hall's developmental psychology, the dangerous child and adolescence, the child's salvation proposal, the Congresses and international events were some of the determinations that contributed to the implementation of the tutelary model based on the doctrine of the irregular situation in Latin America. To show how different factors converged to change the legal and social order, we analyzed this course in five countries: Argentina, Brazil, Chile, Mexico and Uruguay.

KEYWORDS: Socioeducation Policies. Menorismo. Psychology of Development.

\section{Introdução}

El estudio histórico de las leyes mexicanas no ha de excluir ninguno de sus periodos por razones políticas, nacionalistas o de cualquier otra índole: la historia no se puede negar $^{2}$ (Maria Eugenia Vásquez Laslop).

A América Latina é uma construção histórica que possui nome, ideia, interesses e nascimento marcados simbolicamente na modernidade. A construção do nome consolidou-se sob a influência dos europeus, esquecendo-se de valorizar os povos aborígenes, indígenas ou negros que aqui estavam. "Sempre da perspectiva europeia, a América Latina foi se estabelecendo no mundo ocidental moderno como periferia, inferiorizada e explorada" e, apesar de não existir uma única identidade latino-americana, desde fins do século XIX aceitou-se esta nomenclatura. Definir a América Latina em termos geográficos e cultural é algo bastante complexo, bem como classificar e determinar quais são os países latino-americanos, frente à diversificação política, econômica, linguística, cultural e étnica. Portanto, é necessário compreender que quando utilizamos o termo não está sendo considerado "[...] os povos originários da região, nem os povos africanos transplantados ao longo de séculos para cá" (FARRET; PINTO, 2011, p. 31). Apesar disso, as pesquisas em diversas áreas demonstram que existem tendências nas orientações políticas para o conjunto de países denominados latinoamericanos.

Considerando-se que a América Latina não é um espaço geográfico ou continente, mas sim uma expressão utilizada comumente para se referir aos países colonizados por europeus que falam língua neolatina (Portugal, Espanha e França), neste estudo buscamos identificá-los

${ }^{2} \mathrm{O}$ estudo histórico das leis mexicanas não deve excluir nenhum de seus períodos por razões políticas, nacionalistas ou de qualquer outra índole: a histórica não se pode negar. 
utilizando como critério a língua oficial e a localização geográfica em relação ao México ${ }^{3}$. Nessa perspectiva, o artigo insere no debate das tendências políticas para a América Latina a construção da política para a infância no final do século XIX, início do século XX. Para delimitar o estudo, a pesquisa centrou-se em analisar a construção das normativas menoristas em cinco países, sendo eles: Brasil, Argentina, Uruguai, México e Chile.

Convencionou-se denominar Socioeducação a política que foi implementada posteriormente à promulgação do Estatuto da Criança e do Adolescente, na década de 1990, sob a ampla influência dos organismos internacionais pertencentes à Organização das Nações Unidas (ONU). Convém mencionar, entretanto, que a atuação de tais agências especializadas sob a promulgação das políticas para a infância e juventude se iniciou com a organização de Congressos, antes mesmo que a própria ONU - e a sua antecessora, Liga das Nações - fossem criadas e estivessem consolidadas como responsáveis por mediar os conflitos e, supostamente, manter a paz mundial.

No final do século XIX, os Estados Unidos da América (EUA) iniciaram um movimento para tornar os Congressos Penitenciários, que já eram realizados naquele país, um movimento internacional ${ }^{4}$. O primeiro desses congressos foi realizado em Londres em 1872, e reuniu pessoas de 22 países, dentre eles, o Brasil. Com o objetivo de recolher estatísticas penitenciárias e convocar outras conferências, tais Congressos terminaram por incentivar a reforma penal e organizar a política de atendimento, não apenas dos presos adultos, mas também de crianças e adolescentes. Tais congressistas que se reuniram com a pretensão de discutir o aprisionamento de adultos - como uma massa única - foram aos poucos inserindo o debate sobre a separação de cada um dos grupos, supostamente com vistas a combater a imoralidade existente na convivência entre os diferentes, ou seja, homens, mulheres, crianças, adolescentes e jovens (ZANELLA, 2014; 2018).

O artigo aborda inicialmente os motivos históricos, sociais e políticos e os embasamentos ideológicos que contribuíram para que os EUA pusessem em marcha o

\footnotetext{
${ }^{3}$ Baseado nesse critério, os 20 países que compõem a América Latina estão localizados: na América do Norte, o México; na América Central, Costa Rica, El Salvador, Guatemala, Honduras, Nicarágua, Panamá, Cuba, República Dominicana, Haiti; e, todos os países da América do Sul, sendo eles: Argentina, Bolívia, Brasil, Chile, Colômbia, Equador, Paraguai, Peru, Uruguai e Venezuela.

${ }^{4}$ Até o século XVIII, a Europa era o centro do pensamento e da produção teórica e prática sobre formas de punir o criminoso, a exemplo do panóptico utilitarista de Jeremy Bentham e da percepção de que os presos deveriam trabalhar. Entretanto, a partir do final do século XVIII, com a implementação de modelos prisionais considerados inovadores, houve uma inversão, e o movimento internacional das prisões passou a ser proposto dos Estados Unidos da América (EUA) para a Europa e para a América Latina (ZANELLA, 2018).
} 
movimento menorista ${ }^{5}$. Na análise nos deteremos em compreender os pressupostos que fundamentaram o menorismo como uma política que objetivou separar crianças e adolescentes do cumprimento da pena com os adultos. Em seguida, o estudo discorre sobre as normativas publicadas nos países pertencentes à América Latina naquele período histórico, e demonstra como esta influência persistiu durante a elaboração da Convenção sobre os Direitos da Criança.

\section{O contexto histórico, social e político e o embasamento ideológico do menorismo}

A trajetória histórica da responsabilização de crianças, adolescentes e jovens teve início com a etapa de caráter penal indiferenciado, que possuía um caráter retribucionista desde o nascimento dos códigos penais. Durante esse período, os menores de idade eram recolhidos nos mesmos locais que os adultos. No Brasil, esse modelo foi marcado pelo Código Criminal de 1830 e pelo Código Penal de 1890, mas os demais países da América Latina também seguiram a mesma lógica. Entretanto, anterior ao processo de independência jurídica, os países colonizados da América seguiam as ordenações elaboradas pelos colonizadores.

A repulsa moral foi a justificativa para a implantação do modelo penal tutelar. A ideia de separar menores de adultos no cumprimento da pena nasceu nos Estados Unidos, com a criação de uma instituição denominada New York Juvenil Asylum/Asilo da mocidade de Nova Iorque, em $1851^{6}$. A criança permanecia na instituição - que recebia fortes subvenções sociais do Estado - sentenciadas por of probation/liberdade condicional, de maneira que não fossem recolhidas em um estabelecimento prisional ou correcional. Em 1874, a primeira escola pública daquele país, localizada em Michigan, passou a recolher crianças pobres e abandonadas que ficavam sob os cuidados de uma mãe de família que permanecia responsável por cuidar, dar educação moral e religiosa, assistir as refeições e recreios, ensinar ofícios industriais e agrícolas, fornecendo também instrução primária. Dois anos depois, o país criou o Reformatório Elmira para receber rapazes condenados para ministrar o ensino escolar (ZANELLA, 2018).

A organização de tais instituições foi um dos reflexos do empobrecimento massivo das classes populares. Crianças e adolescentes pauperizados, destituídos de espaços regulares de

${ }^{5} \mathrm{O}$ termo delinquente juvenil foi cunhado nos Estados Unidos em 1810 e, em 1824, promulgou-se, na cidade de Nova Iorque, a primeira legislação definindo quem eram tais delinquentes juvenis. Na lei, os delinquentes possuíam, necessariamente, menos de 21 anos idade (ZANELLA, 2018).

${ }^{6} \mathrm{~A}$ instituição foi fundada por um grupo de empresários e profissionais para conter a vagabundagem das crianças pobres da cidade e foi projetada para ser um lugar para crianças não delinquentes, como alternativa às instituições correcionais para delinquentes. Em 1920, a instituição foi renomeada para Aldeias Infantis e continua a operar sob esse nome hoje, com forte incidência na América Latina, inclusive no Brasil (ZANELLA, 2014). 
controle - dentre eles, escolas com o esperado disciplinamento - e a idealização do núcleo familiar burguês contribuíram para que um grupo de reformadores propusesse a institucionalização dos jovens com a criação dos famosos Tribunais de Menores (ZANELLA, 2014; 2018).

Conter a massa juvenil pobre que era filha do proletariado, principalmente imigrante, era urgente, especialmente depois do Tumulto da Haymarket que ocorreu em $1^{\circ}$ de maio de 1886 ${ }^{7}$. Não coincidentemente, foi também em Chicago que foi criado, três anos depois, o primeiro Tribunal de Menores com a promulgação da Juvenile Court Act/Lei das Cortes Juvenis. A lei eliminou as formalidades judiciais para supostamente melhor proteger e controlar crianças, adolescentes e jovens, e anulou a distinção entre infração, abandono e maltrato, o que contribuiu para que os chamados menores não necessariamente necessitassem cometer um crime para serem institucionalizados, já que a institucionalização só visava o seu bem-estar (ZANELLA, 2014; 2018).

Assim, no âmbito das políticas de atendimento da justiça juvenil, a separação de adultos e menores na execução da pena; a criação de tribunais especiais para a responsabilização dos menores; a institucionalização da liberdade condicional; a organização de instituições de correção e reformatórios; e, a destituição da tutela das famílias pobres foram algumas das consequências do embate entre o socialismo e o capitalismo que começava a ganhar polarização internacional no final do século XIX. Foi nesse período que as leis passaram a agir sob a doutrina da situação irregular. Antes da situação irregular, quando um menor cometia um crime, era penalizado pelo modelo retribucionista, ou seja, havia uma proporcionalidade de um terço da pena aplicada para um adulto. Na doutrina menorista os pais perdiam a tutela sobre seus filhos quando um menor cometia um crime. Além disso, não era necessário praticá-lo para ser institucionalizado, já que o fato ocorria para promover o bem-estar do menor. Portanto, quanto mais tempo ficasse institucionalizado melhor seria para ele, o que contribuiu para que não houvesse um limite temporal e ficava a cargo do juiz de menores determinar esse período temporal.

O modelo, denominado tutelar, trouxe, para o Estado, a tutela da criança seguindo o princípio de parens patriaelpai da pátria, que se refere ao poder de política pública do Estado

${ }^{7} \mathrm{Na}$ ocasião, o movimento sindical de Chicago, Estado de Illinois, nos EUA, entrou em conflito com a Polícia durante a realização de um comício. Depois de várias tentativas diárias de esparramar os grevistas, um agente disfarçado jogou uma bomba contra a multidão, o que teve como resultado a morte de sete policiais. Decorrente do fato, sete líderes anarquistas foram condenados à pena de morte, o que foi, posteriormente, revisto. A polarização da luta de classes e a magnitude do caso levaram a II Internacional dos Trabalhadores a registrar a data de $1^{\circ}$ de maio nos anais da história dos movimentos sociais de trabalhadores (ZANELLA, 2018). 
de intervir contra um pai ou guardião legal, retirando o pátrio poder dos genitores, especialmente quando pobres. Além disso, a doutrina possuía e possui como característica a utilização do termo menor.

No modelo tutelar, o termo menor deixou de ser utilizado apenas para marcar a diferença em relação à idade do adulto, ou uma contraposição matemática de oposição ao termo maior, mas passou a significar um conceito que segregava e diferenciava as crianças e os adolescentes pertencentes a uma determinada condição social e a um modelo de família nuclear burguês; o menor se tornou a criança pobre, pertencente às famílias que também foram estigmatizadas como desestruturadas, porque não obedeciam ao modelo estabelecido pela burguesia. Assim, a carência material da família justificava a perda do pátrio poder. Nos EUA, esse movimento ficou conhecido como Child Savers/Salvadores da infância, porque partiu de um grupo de pessoas de classe média alta, imbuídas de moralidade, que se propuseram a retirar as crianças da influência de adultos criminosos presos e das promiscuidades estabelecidas nas prisões ${ }^{8}$ (ZANELLA, 2014).

A polarização da luta de classes contribuiu para que os reformadores propusessem políticas contrarrevolucionárias que tomaram dois rumos diversos contra o avanço do socialismo: o fundamentalismo religioso e a reforma das instituições. O fundamentalismo partia da concepção de que era necessário evangelizar para que o fermento do socialismo não estabelecesse um reino de terror nos EUA. A reforma das instituições buscava a aceitação do sistema capitalista norte-americano em seu conjunto. Foi nesse período que Stanley Hall, psicólogo e educador norte-americano criou a linha de child study/estudo da infância como uma nova disciplina científica, que buscava estabelecer um nexo entre os estudos científicos da criança e a educação, a ela destinada. Assim, o movimento social propunha salvar as crianças ao mesmo tempo em que garantia a salvação do futuro da sociedade estadunidense, longe do socialismo.

Convém mencionar que Stanley Hall foi amplamente influenciado pela Teoria da Origem das Espécies de Charles Darwin, em um período marcado pela passagem dos estudos empíricos e metafísicos - baseados em teorias filosóficas e religiosas - para um momento que os estudos buscavam um intenso alinhamento entre as ciências biológicas, a medicina, a psicologia e, em menor monta, a pedagogia. Portanto, quando a Psicologia do Desenvolvimento, sustentada na teoria evolucionista de Darwin e dos seus seguidores

${ }^{8}$ A amplitude do movimento de separação, que já era ensaiado timidamente na Europa, ganhou força com a criação do primeiro Tribunal Especial para Menores. Depois de Illinois rapidamente outras 30 cidades o fizeram e, em 1932, já havia mais de 600 tribunais nos EUA. 
apresentou a tese da adolescência problema, ela foi útil para a criação dos Tribunais de Menores. Essa análise foi confirmada por Warde (2014), que ao estudar os temas mais debatidos no periódico Pedagogical Seminary/Seminário Pedagógico coordenado por Hall identificou que as observações e experimentos destacados no Child study/Estudo da infância insistiam em temas que evidenciavam situações em que estavam presentes "[...] o vício, a criminalidade, a rivalidade [e] a formação de gangs entre os jovens adolescentes" (sic!) (WARDE, 2014, p. 259).

A teoria do desenvolvimento foi, aos poucos, ganhando mais e mais adeptos, bem como outras fundamentações que a ela foram associadas: de Sigmund Freud vieram os argumentos da psicanálise; Erik Erikson introduziu a teoria do desenvolvimento e a psicanálise ao campo da antropologia cultural, destacando o impacto da experiência social durante o curso da vida; Margaret Mead contribuiu com uma análise antropológica, relacionando a rebeldia da puberdade como uma fase universal ao aspecto da inserção cultural; Jean Piaget estabeleceu que, por meio da assimilação e da acomodação, o adolescente compreenderia a sua realidade, construindo sistemas filosóficos, éticos e políticos como tentativa de se adaptar e mudar o mundo.

$\mathrm{Na}$ América Latina tais autores foram muito utilizados e influenciaram teóricos como Arminda Aberastury, que contribuiu com a disseminação da concepção de adolescência problema, tornando-se um referencial bastante estudado nos cursos de Pedagogia, Psicologia e Psicopedagogia (ZANELLA, 2018). Além disso, muitos livros e formadores da área da socioeducação sempre buscam os argumentos do desenvolvimentismo para explicar o comportamento rebelde dos adolescentes, ainda no contexto atual.

De maneira simplificada, a concepção de Hall era a de que o organismo do indivíduo, durante o desenvolvimento, passava por estágios semelhantes aos que ocorreram com a humanidade ao longo da história, e isso se tornou parte da sua estrutura genética, promovendo comportamentos socialmente inaceitáveis em uma idade (a adolescência) e que tais comportamentos desapareceriam em outros estágios do desenvolvimento (adultez). Nessa perspectiva, a adolescência seria uma fase de oscilação entre extremos: superatividade seguida de indiferença, letargia, desprezo; alegria exuberante, gargalhadas e euforia, depressão e melancolia e assim por diante. Os elementos da psicologia evolutiva e da biologia foram integrados ao campo da aprendizagem e do desenvolvimento humano, o que passou a influenciar as teorias educacionais e pedagógicas a partir de então. 


\section{A influência estadunidense na América Latina: dos interesses econômicos aos cuidados com os menores}

Desde o final do século XIX, os Estados Unidos preocupavam-se com a influência europeia na região latino-americana. Essa preocupação estava relacionada com o fato de que houvesse um retrocesso em relação à independência formal desses países, o que justificava a interferência na parte sul do continente de maneira a impedir que a antiga ordem colonial e mercantilista se estabelecesse. Para alcançar tal objetivo, em 1823 o presidente James Monroe propôs a criação de um sistema americano que se embasasse unicamente nos princípios econômicos liberais. A Doutrina Monroe ou a América para os Americanos considerava a influência europeia um perigo para a paz e a segurança da América.

Portanto, a partir do momento em que a interpretação da mensagem de Monroe ao Congresso começou a ser articulada como elemento de formulação da política externa dos Estados Unidos em relação aos demais países do continente, entrou em vigor a Doutrina Monroe. Os EUA sabiam que não conseguiria competir ainda com o poder econômico e político da Europa, portanto, precisava encontrar mercado próximo, ou seja, na América Latina, o que contribuiu para a organização da Conferência Pan-Americana. A primeira Conferência foi realizada em 1889, em Washington e, além de visitas a lugares prósperos para impressionar os delegados com seu crescimento econômico, mencionava-se tratados de reciprocidade com a América Latina. Essa reciprocidade econômica, entretanto, só foi efetivada quando houve interesse dos EUA à custa da inferioridade latino-americana (MENEZES, 2017).

Depois da primeira Conferência vieram outras - México (1901), Rio de Janeiro (1910), Buenos Aires (1923) - que tiveram como resultado o firmamento de acordos, tratados e a criação da União Pan-Americana, estabelecida em 1890, que aos poucos foram ganhando especialização nos debates: comercial; sanitário/médico; higiênico; pedagógico; instrucional; assistencial; de proteção à infância; de pediatria; da criança, ou seja, iniciativas que passaram a se aproximar do universo infantil. Tais conferências, também, terminaram por contribuir para a problematização sobre a identidade ambígua do continente (pan-americano defendido pelos EUA; latino-americano defendido pela Argentina, ou ainda, hispano ou apenas americano) (NUNES, 2011).

Em 1910, o Congresso Científico Internacional, realizado em Buenos Aires, na Argentina, acolheu a indicação para que fosse organizado um Congreso Americano del Niño. Inicialmente, os Congressos eram grandes reuniões científicas, intelectuais e políticas que buscavam estabelecer a cooperação entre os governos da região; posteriormente, a infância ganhou o centro do debate, como parte das relações interamericanas e os seus projetos para o 
futuro (NUNES, 2011). Ou seja, era necessário educar os sujeitos que iriam defender os preceitos que os EUA defendiam. Posteriormente, essa tendência contribuiu para que a Organização dos Estados Americanos (OEA) - criada em 1948 - assumisse o papel de auxiliar os Estados da região em suas reformas das políticas para a infância o que, posteriormente, influenciou na publicação da Conferência sobre os Direitos da Criança e nas leis que os diferentes países promulgaram sob a nova égide.

\section{O menorismo na América Latina}

Em 1874, o Decreto nº 5.532 criou dez escolas públicas de instrução primária na Corte e destinou uma delas para servir de casa de asilo para meninos desvalidos que possuíssem idade abaixo de 12 anos. A Casa de Asylo dos Meninos Desvalidos foi a primeira instituição pública de atendimento para meninos e meninas abandonadas da Corte, e seguindo os moldes de outras instituições de Portugal e da Europa, combinava instrução e trabalho para a superação da indigência. Em 1883, quase uma década depois, o Decreto n ${ }^{\circ} .8 .910$ criou o regulamento da instituição e estabeleceu que fossem admitidas no Asylo crianças pobres que não eram órfãos, pela primeira vez.

A Roda dos Expostos só seria extinta em 1927, mas, no final do século XIX, o Governo já se considerava no direito de tomar para si a responsabilidade de cuidar dos filhos dos pobres, ao invés de pensar em condições para que estes mesmos o fizessem. O Decreto de 1883 é um marco, pois, pela primeira vez aparece na legislação do Brasil que seriam admitidas na instituição crianças que não eram órfãs de pai e mãe. A idade para fazê-lo ficou estipulada em oito anos, idade que as crianças já poderiam trabalhar para manter a instituição, seguindo a perspectiva utilitarista do período. Convém mencionar que o decreto estabeleceu ainda que se os pais ou parentes de algum asilado desejasse retirar a criança do local por se achar em condições de cuidar de sua educação, o Ministro do Império mandaria entregá-lo se julgasse conveniente, mas os reclamantes deveriam indenizar o Estado (ZANELLA, 2018).

Em 1890, o chefe do governo provisório, Deodoro da Fonseca, publicou o decreto $\mathrm{n}^{\circ}$. 439 e antecipou em três décadas o menorismo, estabelecendo as bases para a organização da assistência à infância desvalida. O documento definiu que o Asylo de Meninos Desvalidos estava destinado a receber, manter e educar menores desvalidos. Na legislação é possível observar, no final do século XIX, que o termo menor já fazia parte do arcabouço jurídico brasileiro. Tal evidência nos permite contrariar juristas que argumentavam que a primeira 
legislação menorista da América Latina foi a Ley Agote, publicada na Argentina em 1919. Segundo Emílio García Méndez:

O tratamento jurídico diferenciado da infância-adolescência na América Latina remonta às primeiras décadas do século XX. Em 1919, é promulgada na Argentina a primeira legislação específica, a Lei 10.903, mais conhecida como Lei Agote. Até então, a única diferenciação normativa existente encontrava-se nos ainda vigentes códigos penais retribucionistas do século XIX. Em geral, tal especificidade se limitava a reduzir as penas em um terço, tratando-se de autores de delitos com idade inferior a dezoito anos (MÉNDEZ, 1988, p. 21).

$\mathrm{Na}$ verdade, entende-se que a Argentina foi a primeira a introduzir na América Latina um juizado específico para menores, seguido de diversos outros países, mas isso também é contestado. Verdadeiramente, a Ley Agote modificou o artigo 264 do Código Civil de 1869 Ley $\mathrm{n}^{\circ} .340$ - que tratava, no Título IX, dos menores, nos artigos 126 a 139. Convém mencionar que no Código Civil o termo menor era utilizar para estabelecer uma relação entre maior idade e menor idade, no sentido matemático. A Ley do Patronato ou Agote instaurou na Argentina o menorismo com o sentido que estamos analisando, ou seja, consolidou o ideário punitivo, mas apesar de ter criado juízes especialistas em matéria da infância não criou, literalmente, os Tribunais de Menores que tivessem juízos únicos e especializados, o que se tornou um clamor dos congressistas que participaram da Primera Conferencia sobre Infancia Abandonada y Delincuente, realizada em 1933, o que, possivelmente, impulsionou a sanção da Ley $n^{\circ} .4 .664$ de 1937 e criou efetivamente, em 1939, o primeiro Tribunal de Menores na província de Buenos Ayres (STAGNO, 2008).

Em 1911, a Lei nº 3.738 - Código Civil - promulgada no Uruguai definiu os casos de perda e restituição da custódia, retirada de guarda de crianças, correção de menores infratores e a criação do Consejo de Protección de Menores/Conselho para a proteção de Menores. Além de mencionar por 45 vezes a terminologia menor, estabeleceu ser função do tal Conselho: “Organizar, inspeccionar y vigilar los establecimientos públicos en que se coloquen los menores, tomando todas las disposiciones conducentes a los fines que persigue esta ley" (URUGUAY, 1911, art. 44, § 6º), bem como "Provocar, [...] la formación de colonias donde se colocarán los que salgan de los establecimientos públicos a la edad establecida por los reglamentos"9 (URUGUAY, 1911, art. 44, § $8^{\circ}$ ). Ou seja, diferentemente do Brasil, a Lei

9 “Organizar, inspecionar e supervisionar os estabelecimentos públicos em que os menores são colocados, tomando todas as providências condizentes com os propósitos perseguidos por esta lei”, bem como, "Provocar, [...], a formação de colônias onde aqueles que deixam os estabelecimentos públicos na idade estabelecida pelos regulamentos serão colocados" (Tradução livre da pesquisadora). 
preocupava-se com o local para o qual os menores iriam depois de permanecerem institucionalizados.

Os menores ficavam sob a custódia da autoridade pública nos seguintes casos: a) perda de autoridade parental dos pais sobre seus filhos em caso de manifestação de desinteresse, ou ainda, se o juiz assim o determinasse por terem sido condenados por delitos como autores ou cúmplices, contra seus filhos; condenados por crimes comuns, e ainda, por corrupção de menores, bem como por prática habitual de embriaguez, maus tratos ou negligência; e, b) por cometimento de crimes, sendo eles maiores de dez e menores de 18 anos. Para tanto, o já mencionado Conselho deveria "Establecer la distinción entre los menores delincuentes, los viciosos y los simplemente abandonados, a fin de mantenerlos en la más absoluta separación [...] ${ }^{10 "}$ (URUGUAY, 1911, art. 44, § 2º ). A Lei ainda estabelecia que: "Los menores serán colocados preferentemente en las casas de familia o bien en escuelas agropecuarias y profesionales siendo varones, y siendo mujeres en establecimientos de enseñanza, labores y oficios o profesiones de su sexo $[\ldots]^{11 "}$ ou ainda, inseridos em estabelecimento disciplinar ou de correção, pelo tempo que os regulamentos determinarem (URUGUAY, 1911, art. 53).

Em 1934, a Lei $n^{\circ} .3 .738$ foi integrada ao Código $n^{\circ}$. 9.342, denominado Código del Niño, que ao ser aprovado introduziu modificações relacionadas à proteção da primeira e segunda infância e pré-natal, regulando também a situação das crianças abandonadas, da perda e da reabilitação da autoridade parental, dentre outras questões. Além disso, criou o Juizado de Menores, tornando o juiz o único competente para responder pelos menores.

A Constituição de 1917 do México construiu um projeto de nação para um país que tivesse ordem e progresso, aos moldes dos preceitos positivistas da época. Para tanto, o crime atrapalhava o avanço almejado, assim era necessário estudar e normatizar os ditos anormais. Independente, o país promulgou as primeiras normativas que tratavam dos menores e, sobre a influência dos Estados Unidos e do Congresso Criminológico celebrado no país em 1923, criou o primeiro Tribunal de Menores em San Luís Potosí. De qualquer maneira, o Código Civil de 1926 ainda utilizava o termo menor sob a perspectiva de oposição ao termo maior. No ano seguinte, entretanto, criou a primeira Junta Federal de Proteção à Infância e, em 1929, pela primeira vez, o Código Penal incluiu os menores no sistema penal.

10 "Estabelecer a distinção entre delinquentes juvenis, viciosos e simplesmente abandonados, a fim de mantê-los na mais absoluta separação [...]" (Tradução livre da pesquisadora).

11 “Os menores serão colocados preferencialmente em casas de família ou em escolas agrícolas e profissionais sendo do sexo masculino, e sendo mulheres em estabelecimentos de ensino, empregos e profissões ou seu sexo [...]" (Tradução livre da pesquisadora). 
Data de 1855 o primeiro Código Civil Chileno. O mesmo estabeleceu no artigo 26 os termos utilizados para cada fase do desenvolvimento, sendo criança aqueles que não tivessem cumprido sete anos, impúberes o homem que não houvesse cumprido 14 anos e a mulher que não houvesse cumprido 12 anos; adulto aquele que não fosse mais puro; além disso, era maior de idade ou simplesmente maior, aquele que tivesse cumprido 18 anos; e menor de idade ou simplesmente menor, aquele que não tivesse cumprido. Ou seja, como podemos observar o tratamento dado aos menores e maiores era o mesmo. O Título XXIII da Lei apresentou nos artigos 435 a 441 as Reglas especiales relativas a la curaduria del menor/Regras especiais relativas à curadoria do menor e trata explicitamente dos direitos civis de menores emancipados pelos pais, o que demonstra que não existia diferença terminológica no tratamento (MÉXICO, 1855).

Em 1912, a Lei nº 2.675 ainda mesclava o termo infância com o termo menor e menor impúbere, mas, em 1928, a Ley nº 4.447 organizou a Dirección General de Protección de Menores/Direção Geral de Proteção aos Menores e determinou que fossem criados os Juizados de Menores e as Casas de Menores com espaços para exames médicos e psicológicos de observação e classificação dos menores.

\section{Tendência educativa, política e moral para os filhos dos pobres}

A pesquisa é sempre resultado de um processo de sistematização, mas a sua produção é mais que uma justaposição de fragmentos de textos ou de informações. Os estudos sobre políticas têm se configurado como uma metodologia para desvelar os interesses em disputa na área da educação. Nesse aspecto, tem contribuído também para demonstrar que os discursos, a produção jurídica e normativa da área da infância e juventude possuem marcas e respondem a um projeto de sociedade que busca atender a um aspecto ideológico e historicamente determinado. Portanto, o estudo apresentado visa compreender o objeto analisado em todas suas determinações, para que seja possível atuar de maneira coerente em relação a ele.

O estudo em políticas tem contribuído para demonstrar que as legislações promulgadas no Brasil não são políticas desinteressadas e desarticuladas do contexto da América Latina, da Europa e dos Estados Unidos; ao contrário, pois, tem sido desde o início, como demonstramos, resultado de interesses internacionais e gestadas para operacionalizar tais interesses.

Tais interesses foram também os principais mobilizadores das mudanças normativas que ocorreram na década de 1990, quando o Estatuto da Criança e do Adolescente foi promulgado, 
especialmente se considerarmos que um ano antes a ONU promulgou a Convenção sobre os Direitos da Criança (CDC). A Convenção foi um acordo global, internacional e vinculativo, adotado pela Resolução no. 44/25 da Assembleia Geral da ONU em 20 de novembro, de 1989. O documento faz parte dos sete tratados da Organização sobre direitos humanos e pretendia romper com o modelo tutelar implantado entre o final do século XIX e início do século XX. Tal rompimento contribuiu para que a Organização fosse considerada a maior defensora de tais direitos, desconsiderando uma aproximação de interesses quando as leis anteriores foram promulgadas.

Pilotti (2000), ao analisar o papel desempenhado pelos Estados, Organizações Intergovernamentais, Organismos Internacionais e OINGs ${ }^{12}$, no Grupo de Trabalho de elaboração do texto da Convenção, identificou que os governos dos países latinos americanos participaram ativamente das sessões realizadas durante o período de 1981 a 1988: a Argentina e o Brasil se fizeram presentes em nove sessões, Cuba em oito, Peru em sete, Venezuela em seis, México em cinco, Colômbia em quatro, Nicarágua em três, Panamá em duas e Bolívia, Costa Rica, Honduras e Haiti em uma sessão cada. Ao analisar a atuação das OINGs, o autor constatou que houve uma participação consideravelmente superior à atuação das Agências, Fundos e Programas da ONU que atuam na área da infância, visto que houve um aumento nessa participação apenas na segunda leitura do texto final da Convenção.

Nos grupos de trabalho para a elaboração da Convenção, a presença das OINGs foi constante mas limitada até 1983, quando foi constituído um grupo ad hoc que passou a se reunir a cada dois anos, com o objetivo de analisar as propostas apresentadas pelos países e elaborar sugestões de artigos. Dentre as OINGs mais ativas, identificou-se a participação das filiais da Suécia e da Grã-Bretanha da Save the children que, por possuírem uma vasta rede de contatos na América Latina e Caribe, encarregaram-se de difundir nesses locais o conteúdo das discussões (ZANELLA, 2014).

Para alcançar os objetivos de promoção e implementação dos direitos estabelecidos na Convenção, o Fundo das Nações Unidas para a Infância (UNICEF) estabeleceu três etapas:

Primeramente, se promueve la ratificación del instrumento internacional, para lo cual se trabaja principalmente con las ramas ejecutiva y legislativa, fase que en América Latina se completa a mediados de los noventa. Seguidamente, se busca asegurar que exista compatibilidad entre las disposiciones de la Convención y las contenidas en la leyes nacionales. En esta etapa la OIG promociona la necesidad de emprender reformas legislativas, de acuerdo a las

${ }^{12}$ Pilotti (2000) utiliza a nomenclatura Organizações intergovernamentais (OIG/OIGs) para os Fundos, Programas e Agências Especializadas da ONU e utiliza o termo Organizações internacionais não-governamentais (OING/OINGs) para definir aquelas que possuem atuação internacional. 
especificidades de cada país, y brinda asistencia técnica a los sectores legislativo, ejecutivo y judicial en la elaboración de los proyectos de ley requeridos. Durante los noventa, UNICEF concentró parte importante de su trabajo en esta área, esfuerzo que contribuyó significativamente a impulsar las reformas legislativas realizadas, o en curso, en más de una docena de países latinoamericanos ${ }^{13}$ (PILOTTI, 2000, p. 51).

A terceira e última etapa, mais difusa e de longo prazo, orientou as reformas institucionais necessárias para gerar o que a Comissão Econômica para a América Latina e o Caribe (CEPAL) denominou - referindo-se ao impacto desejado da Convenção na América Latina - de cultura de direitos. Essa cultura consolidaria uma nova perspectiva e uma mudança qualitativa fundamental na percepção legal e social da infância, cujos efeitos de ambas as políticas estatais afetariam as atitudes, valores e sensibilidades das pessoas (ZANELLA, 2014).

Importante mencionar que, tradicionalmente, a elaboração de um tratado da ONU é realizada em duas etapas. Na primeira é realizada a redação básica do texto. Essa etapa é conhecida como primeira leitura. Na segunda, o texto é revisado e finalizado. No caso da Convenção, a primeira etapa foi realizada durante sessões de uma semana cada entre os anos de 1979 e 1987 e uma sessão final de duas semanas, em 1988. A segunda leitura foi realizada durante duas semanas nos meses de novembro/dezembro de 1988. O texto foi adotado e aprovado pela Comissão de Direitos Humanos em março de 1989 (ZANELLA, 2014).

Diferentemente dos demais países, o Brasil não esperou a aprovação, ratificação e promulgação da Convenção internamente para dar o próximo passo. Ao contrário, antecipouse sancionando, em 13 de julho de 1990, o Estatuto da Criança e do Adolescente, que entrou em vigor em outubro do mesmo ano. Ocorre que passadas quase três décadas da aprovação do Estatuto, o modelo tutelar da doutrina da situação irregular ainda orienta a execução da política, apesar de o termo menor ter sido abolido juridicamente, o que tem encetado debates sobre a diminuição na idade para a responsabilização de menores de 18 anos. Assim, de um lado encontram-se os partidos e políticos de direita defendendo a alteração na Lei e; de outro, a esquerda defendendo que a responsabilização permaneça aos 18 anos de idade. Entretanto, considerando-se que o modelo tutelar promoveu um aumento considerável nessa

13 "Primeiro, se promove a ratificação dos instrumentos internacionais, para a qual trabalha, principalmente, com poderes executivo e legislativo. A fase latino-americana foi concluída em meados dos anos noventa. A segunda etapa busca garantir que haja compatibilidade entre as disposições da Convenção e as normas constantes de leis nacionais. Nesta fase, o Fundo promove a necessidade de reformas legislativas, de acordo com as especificidades de cada país, e fornece assistência técnica para o legislativo, executivo e judiciário no desenvolvimento dos projetos necessários. Durante os anos de 1990, o Unicef focou parte do seu trabalho nesta área, um esforço que contribuiu, significativamente, para aumentar as reformas legislativas, ou em andamento, em mais de uma dúzia de países latinoamericanos" (Traduzido pela pesquisadora, 2014). 
institucionalização e o número de jovens institucionalizados no Brasil tem aumentado de maneira expressiva, não seria conveniente perguntar: será que estamos lutando do lado certo?

\section{Considerações finais}

No período de forte contestação do modelo tutelar regulado pela doutrina da situação irregular, com vistas a conquistar a aprovação de uma legislação orientada por um paradigma sustentado na doutrina da proteção integral, o Brasil saiu na frente e aprovou uma legislação que se tornou um marco na área da infância, o Estatuto da Criança e do Adolescente. A aprovação dessa lei seguiu a orientação dos organismos internacionais e agências especializadas da Organização das Nações Unidas.

A promulgação contribuiu para que a ONU passasse a ser apresentada como grande defensora dos direitos de crianças e adolescentes. Entretanto, as pesquisas realizadas seguindo a metodologia de análise de políticas contribuíram para evidenciar que a Organização possui lado no debate sobre o problema, e ao longo dos anos tem se pronunciado para mediar e resgar os conflitos sociais privando da liberdade crianças e jovens provenientes de famílias vulneráveis na América Latina.

O estudo analisou a elaboração de políticas para crianças, adolescentes e jovens no início do século XX e demonstrou como a organização de diferentes congressos contribuiu alinhando juridicamente o caminho adotado por países como Argentina, Chile, Uruguai, México e Brasil. Convém mencionar que tais mudanças seguiram a orientação dos Estados Unidos, sendo que o modelo tutelar é ainda vigente no American juvenile justice system/Sistema de Justiça Juvenil dos EUA.

AGRADECIMENTOS: Pesquisa realizada com subsídio do Programa de Doutorado Sanduíche no Exterior (PDSE), concedida pela Coordenação de Aperfeiçoamento de Pessoal de Nível Superior (CAPES) - processo $n^{\circ}$. 88881.134314/2016-01 - Edital no 19/2016. Agradeço à Professora doutora Angela Mara de Barros Lara pela qualificada orientação durante o mestrado e doutorado.

\section{REFERÊNCIAS}

FARRET, Rafael Leporace; PINTO, Simone Rodrigues. América Latina: da construção do nome à consolidação da ideia. Topoi (Rio J.), Rio de Janeiro, v. 12, n. 23, p. 30-42, dez. 2011. Disponível em: http://www.scielo.br/scielo.php?script=sci_arttext\&pid=S2237101X2011000200030\&lng=en\&nrm=iso. Acesso em: 14 maio 2019. 
MÉNDEZ, Emílio García. Infância e cidadania na América Latina. São Paulo: Hucitec/Instituto Ayrton Senna, 1998.

MENEZES, Alfredo da Mota. Ingênuos, pobres \& católicos: a relação dos EUA com a América Latina. Rev. Lara Alves. Rio de Janeiro: Bonecker, 2017.

MÉXICO. Código Civil. Santiago, 14 de dezembro de 1855. Disponível em: https://www.leychile.cl/Navegar?idNorma=1973. Acesso em: 20 maio 2019.

NUNES, Eduardo Silveira Netto. A infância como portadora do futuro: América Latina, 1916-1948. (Tese, História Social). São Paulo: USP, 2011.

PILOTTI, Francisco. Globalización y convención sobre los derechos del niño: el contexto del texto. Washington: OEA, 2000.

STAGNO, Leandro. La minoridad en la Provincia de Buenos Aires, 1930-1943: ideas punitivas y prácticas judiciales. (Tese, Ciências Sociais). Argentina, 2008.

URUGUAY. Ley no 3.738 - Código Civil: casos de perdida y restitucion de la patria potestad, tutela de los menores desamparados, correccion de menores delincuentes y creacion del consejo de proteccion de menores. 1911. Disponível em: https://legislativo.parlamento.gub.uy/temporales/leytemp4743231.htm. Acesso em: 15 maio 2019.

URUGUAY. Ministerio de Proteccion a la Infancia. Ley $\mathbf{n}^{\mathbf{0}}$ 9.342: se aprueba, con modificaciones, um proyecto de Código del Niño. 1934. Disponível em: https://www.impo.com.uy/diariooficial/1934/05/02/20. Acesso em 15 maio 2019.

WARDE, Mirian Jorge. G. Stanley Hall e o child study: Estados Unidos de fins do século XIX e começo do século XX. Rev. bras. hist. educ., Maringá-PR, v.14, n.2 (35), p. 243-270, maio/ago. 2014. Disponível em: http://eduem.uem.br/ojs/index.php/rbhe/article/view/38886. Acesso em: 01 jan. 2018.

ZANELLA, Maria Nilvane. A perspectiva da ONU sobre o menor, o infrator, o delinquente e o adolescente em conflito com a lei: as políticas de socioeducação (Dissertação, Educação). Maringá, PR: UEM, 2014. 269 f. http://www.ppe.uem.br/dissertacoes/2014\%20-\%20Maria\%20Nilvane.pdf.

ZANELLA, Maria Nilvane. Da institucionalização de menores à desinstitucionalização de crianças e adolescentes: os fundamentos ideológicos da extinção da FUNABEM como solução neoliberal. 586 f. Tese (Doutorado em Educação). Maringá: Universidade Estadual de Maringá, 2018. 


\section{Como referenciar este artigo}

ZANELLA, Maria Nilvane. A implantação do menorismo na América Latina no início do século XX: tendências jurídicas e políticas para a contenção dos mais pobres. Revista IberoAmericana de Estudos em Educação, Araraquara, v. 14, n. esp. 3, p. 1750-1766, out., 2019. e-ISSN: 1982-5587. DOI: 10.21723/riaee.v14iesp.3.12761

Submetido em: 25/03/2019

Revisões requeridas: 20/04/2019

Aceito em: 15/05/2019

Publicado em: 30/08/2019 